\title{
Organização de novos partidos políticos: entre estratégias de cooptação e contestação $o^{2}$
}

Organization of new political parties: between cooptation and contestation strategies

\section{Introdução}

No período pós-segunda guerra mundial, o aumento expressivo de partidos, que propunham demandas para além da agenda tradicional ${ }^{3}$ na Europa, passou a ganhar atenção de estudiosos (HARMEL; ROBERTSON, 1985; HUG, 2001; ANDREWS; MONEY, 2003; TAVITS, 2006; 2008; LAGO; MARTINEZ, 2011). As preocupações giraram desde aspectos mais normativos, como a definição sobre o que é um novo partido (HUG, 2001; BARNEA; RAHAT, 2010; BIEZEN; RASHKVOVA, 2014) a aspectos empíricos acerca do impacto dessas siglas no sistema partidário (HAUSS; RAYSIDE, 1978; PEDERSEN, 1980; TAVITS, 2006, 2008).

Grande parte dessas preocupações advinham do diagnóstico de que a chamada teoria do "congelamento partidário"4 (frozen party systems) de Lipset e Rokkan (1967) estaria perdendo poder explicativo em razão da entrada de novos agentes políticos - estes, por sua vez, estariam introduzindo novas questões ao debate público,

\footnotetext{
1 Professor Adjunto no curso de graduação em Direito da Fundação Getúlio Vargas (FGV Direito Rio), Rio de Janeiro, RJ, Brasil. E-mail: <decio.rocha@fgv.br>

2 Para replicação de dados ver: https://doi.org/10.7910/DVN/NBIOES

3 Agendas tradicionais giravam em torno das temáticas esquerda-direita, liberais-conservadores, social-democratas, democratas cristãos, entre outras.

4 Os autores desenvolveram essa teoria para explicar como as clivagens sociais que constituíam os principais partidos na Europa entre fins do século XIX e início do século XX pouco se renovavam, já que os partidos europeus entre 1920 e 1960 praticamente tinham a mesma "cara".
} 
como meio ambiente, direitos das mulheres, questões raciais, entre outras. Pedersen (1980) construiu o Índice de Volatilidade Eleitoral (VT), buscando discutir a tese do congelamento partidário. O VT demonstrou que democracias consolidadas mantinham um sistema partidário mais "fechado" em poucos partidos, mas que, em jovens democracias, principalmente no Leste Europeu, não haveria esse "congelamento", mas, sim, maior rotatividade de partidos e lideranças. Essa novidade geraria "instabilidade" ao sistema político, pela baixa formação de preferências (MAINWARING; ESPAÑA-NÁJERA; GERVASONI, 2009).

Diversas teses passaram a discutir causas e consequências na possibilidade de realinhamentos partidários. Entre as teorias centrais destacam-se aquelas que: (i) deram centralidade a valores pós materialistas (INGLEHART, 1977); e (ii) concentraram-se na perda de espaço dos "partidos de massa" duvergeriano para partidos catch-all (KIRCHHEIMER, 1966), que estariam aumentando sua agenda de políticas para além do eixo esquerda-direita.

Essas mudanças ocorreram nos mais diversos sistemas partidários, estendendo-se do Leste Europeu à América Latina e África, tornando-se um fenômeno sociopolítico, que dominou grande parte da agenda de pesquisas internacionais (BOLLIN, 2007; HARMEL; ROBERTSON, 1985; HUG, 2001; MAINWARING, 1999; TAVITS, 2006, 2008; CHHIBBER; KOLLMAN, 2004; BOIX, 2007).

Embora exista essa vasta profusão de estudos no nível internacional, a ciência política brasileira se dedicou pouco a essa temática, mesmo tendo um sistema partidário em que novos partidos se formaram em todas as eleições desde a reabertura. Na década de 1990, Lima Júnior (1993) analisou as características dos partidos surgidos na década de 1980. Outras autoras, como Kinzo (1988), Meneguello (1989) e Keck (1991), investigaram extensivamente a formação do PMDB e do PT, sequencialmente. Porém, como se pode notar, o principal foco desses estudos estava nos maiores partidos, principalmente no PT, o qual mereceu uma atenção substancial.

Apenas recentemente, trabalhos como o de Kestler, Krause e Lucca (2013), além dos estudos de Krause, Schaefer, Barbosa (2018), 
têm buscado empreender uma abordagem socioeconômica e institucional, para dar conta de entender as mudanças e a formação dos partidos na América Latina pós-década de 1980.

A ausência de estudos mais sistemáticos sobre a formação desses novos partidos acrescenta um problema para a ciência política brasileira, principalmente porque, devido ao fato de ser o sistema partidário mais fragmentado do mundo ${ }^{5}$, há diversas análises por parte da mídia e de especialistas que creditam aos novos partidos o problema da crise política brasileira, quando pouco se sabe efetivamente sobre os seus reais efeitos no sistema político. Pouco se sabe realmente sobre como os novos partidos se formam, constroem as próprias listas, buscam apoios em eleições, etc.

Para demonstrar as estratégias de formação dos novos partidos, construímos uma base de dados, que vai 1986 a 2018, analisamos o background de todos os deputados eleitos nesses partidos (filiação anterior, vida política, distrito onde concorrem, entre outros). Por estratégia metodológica, definimos como novo partido todos aqueles que conseguem um registro e que, em uma dada eleição, conseguiram alcançar representação mínima na Câmara dos Deputados (ao menos uma cadeira). Ao todo, foram examinados 42 partidos que obtiveram êxito na disputa para a Câmara dos Deputados desde a redemocratização. Nesse sentido, a nossa unidade de análise são os partidos e a unidade de observação são as eleições. Ao pesquisarmos o surgimento dos partidos por eleição, traçamos as suas estratégias de formação. Com isso, atestamos que dois tipos de estratégias entre os partidos: cooptar elites de partidos estabelecidos ou coordenar a entrada de nomes totalmente de fora da arena representativa. Tais táticas têm impacto distinto sobre a trajetória e o desempenho dos partidos, por todo seu tempo de vida.

Para dar conta da lacuna relativa a estratégias de formação de novos partidos, bem como o seu desempenho eleitoral, este artigo, além da introdução, fixa um panorama do debate normativo sobre

5 Para o Número Efetivo de partidos (NEP) de mais de 100 países, ver GALLAGHER, Michael. Election indices dataset. 2019. Disponível em: http://www.tcd.ie/Political_Science/people/michael_gallagher/ ElSystems/index.php. Acesso em: 28 maio 2019. 
os novos partidos. Na terceira parte, propomos a discussão clássica acerca das origens e do desenvolvimento dos partidos. No tópico seguinte, descrevemos a construção dos dados da pesquisa. Na quinta e na sexta seções, trazemos, por fim, a análise empírica sobre o caso brasileiro e passamos às considerações finais.

\section{O debate normativo sobre novidade política}

A questão associada a quão novos são os partidos políticos ainda gera uma discussão extensa. Esse debate deriva de uma certa polissemia causada pelo termo "novo". A perspectiva metodológica utilizada por cada pesquisador direciona essas argumentações em linhas mais restritivas ou amplas. Barreto (2018) empreendeu esforços de traduzir grande parte das análises por parte da literatura internacional para pesquisas que conferem maior amplitude à investigação de novos partidos. As abordagens com um entendimento mais amplo a respeito do que são os novos partidos (HARMEL; ROBERTSON, 1985; HUG, 2001; TAVITS, 2006; KROUWEL; LUCARDIE, 2008; MUSTILLO, 2009) assim os consideram como todos aqueles que não disputaram eleições anteriores e/ou que conseguiram registro para um partido não existente anteriormente.

Para outras abordagens mais normativas e restritivas, os partidos são novos quando trazem "novas questões"6 à agenda pública, representando grupos programaticamente mais bem definidos com a sociedade (MAINWARING; ESPAÑA-NÁJERA; GERVASONI, 2009; BOLLIN, 2014). Nessa linha, esse surgimento sem vínculos "societais" representa uma ausência de institucionalização do sistema partidário, com impacto na baixa identificação partidária (MAINWARING, 1999; MAINWARING; ESPAÑA-NÁJERA; GERVASONI, 2009). Assim, não seriam "novos", mas parte de uma migração constante de elites políticas em que o label de políticas oferecidas se referencia mais na figura de agentes políticos do que em partidos.

6 Frequentemente lido na literatura como new issues. 
Essas diferentes perspectivas aportam informações distintas sobre o impacto de novos partidos no sistema partidário, no legislativo e no sistema representativo como um todo.

Janda (1980) constrói uma análise demonstrando que, em grande medida, os novos partidos surgem da extinção ou união de nomenclaturas já existentes, trazendo pouca novidade ao sistema partidário. Buscando dar conta de distinguir os que, de fato, são novidade política e os que podem ser apenas elites estabelecidas em nova roupagem, Barnea e Rahat (2010) dão amplitude ao conceito de novo partido, indicando três possibilidades; a primeira seria de um novo partido, que surge com um antigo nome, como parte já constitutiva do sistema, sendo um ator reincorporado e que não deveria ser visto como novo ${ }^{7}$. A segunda é um partido que muda de nome para se dissociar do estabilishment e do mercado político, tentando indicar uma nova alternativa e ser visto como novo ${ }^{8}$. Por fim, um novo partido pode, ainda, utilizar o nome de um partido antigo de modo a aumentar o apelo a seus eleitores dentro de uma história política e expandindo, desse modo, a sua base eleitoral, apresentando um caráter seminovo ${ }^{9}$. Os três componentes apontam para o ponto cognitivo ou, dito de outra maneira, a forma de reconhecimento mais básico de um partido, isto é, o seu próprio nome. Os autores chamam atenção para o caráter multifacetado do surgimento de partidos, já que estes são instituições que se adaptam e se modificam de acordo com a necessidade de sobrevivência em ambientes altamente competitivos.

Sob uma perspectiva que busca dar conta de um caráter mais inovador dos novos partidos, Kestler, Krause e Lucca (2013) apontam para as mudanças ocorridas na América Latina nas últimas quatro

\footnotetext{
7 O Partido Progressista (PP), após diversas fusões, voltou ao cenário com o mesmo nome, podendo ser um exemplo dentro da categoria dos autores.

8 A história política brasileira é recheada de exemplos desse tipo. O exemplo que mais chamou atenção foi a modificação procedida pelo PFL em 2007 para Democratas após uma perda substantiva de representação por todo país. Mais recentemente, o PMDB, após sofrer com várias denúncias de corrupção, também modificou o nome para MDB, para buscar parecer um novo partido.

9 A disputa entre Brizola e Ivete Vargas na década de 1980 para criar um partido com o nome de PTB, que remontaria ao trabalhismo varguista, ilustra bem essa categoria. Uma tentativa de trazer a história do partido.
} 
décadas, como: (i) o deslocamento de uma matriz mais centrada no Estado a uma mais voltada à centralidade do mercado; e a (ii) a crise de representação dos atores coletivos e a mudança no regime político como uma estrutura de oportunidades para partidos de cunho inovador. Tais partidos seriam, então, dotados de capacidade de romper com o sistema de partidos estabelecidos e de incorporar novos atores à participação partidária, fortalecendo, assim, a democracia (KESTLER; KRAUSE; LUCCA, 2013, p. 164).

Como já mencionado anteriormente, cada perspectiva adotada pelos pesquisadores traz resultados distintos sobre o entendimento do impacto dessas novas siglas no sistema político em geral.

Para dar conta da complexidade desse fenômeno no caso brasileiro, vamos partir aqui de uma perspectiva mais minimalista. Nessa perspectiva, um novo partido é aquele que consegue um registro e conquista ao menos uma cadeira na Câmara dos Deputados em uma determinada eleição, estabelecendo um nível mínimo de representação. Esse ponto se assemelha à definição adotada por Biezen e Rashkova (2014), que consideram como novos partidos aqueles formados por cisões ou fusões, excluindo-se outros que apenas mudam de nome. A necessidade de conquista de um novo registro ${ }^{10}$ é condição básica para que um partido seja novo, mesmo que seja construído por lideranças já estabelecidas na política. Um novo partido é parte constitutiva de uma mudança no processo competitivo dentro do sistema partidário. Também, a partir do trabalho de Harmel e Robertson (1985), são considerados novos todos os partidos adicionados ao sistema partidário de um país, não presentes nele anteriormente, portanto. Unindo esses traços teóricos, consideramos que um novo partido conquista um registro e obtém, ao menos, uma cadeira na Câmara dos Deputados.

Essa delimitação abre um amplo leque de possibilidades de análise por ser mais pragmática em termos empíricos e teóricos.

10 A análise de partidos que apenas conseguiram registro, mas não conquistaram representação, expandiria significativamente o nosso objeto, já que, no final da década de 1980 e início de 1990, houve uma explosão de partidos com registros pela baixa restrição desse período. Em sumarização dos partidos brasileiros, identificamos mais de 80 partidos após 1979 que tiveram registro temporário ou definitivo. 
Como já dito, de 1986 a 2018, 42 partidos distintos ganharam espaço na Câmara dos Deputados. Nesse mesmo período, mais de 100 siglas conseguiram registro. Não desconsideramos que analisar a formação de partidos que conseguiram registro, mas não representação, seja de grande importância, mas não abordamos esta questão neste trabalho.

Na próxima seção, retomamos o debate clássico entre a organização inicial dos partidos e o seu desenvolvimento, demonstrando serem categorias essenciais para se entenderem as estratégias de formação e sobrevivência das novas siglas no Brasil.

\section{Organização e desenvolvimento de novos partidos}

As estratégias de formação dos novos partidos têm um caráter fundamental em sua organização e sobrevivência no sistema político. Isso porque se torna um elemento determinante na possibilidade de ação e atuação ao longo do tempo. A organização se torna um importante aspecto para compreender como os partidos vão se movimentar na competição política e como poderão obter sucesso com estratégias de entrada distintas (HUG, 2001; PANEBIANCO, 2005).

Entender quais elementos importam na configuração, a qual irá determinar o perfil dos novos partidos, é essencial para explicar o impacto desses novos partidos no sistema político. O desempenho eleitoral é afetado pela sua estrutura organizacional inicial. É amplamente conhecido pela literatura brasileira que a estrutura da competição comporta um sistema de partidos fortemente ligados à formação de governos (LIMONGI; CORTEZ, 2010; MELO, 2010; BRAGA, 2012; TAROUCO, 2010; MELO; CÂMARA, 2012). Por isso, o perfil constitutivo de grande parte desses novos partidos está relacionado a uma forte relação com a formação de governos. Sua formação inicial - cooptação de elites e agenda de transformação do status quo - torna-se importante ferramenta, constituindo elemento-chave a acompanhar o partido por toda sua trajetória política.

Os partidos novos buscam, em geral, fortalecer-se organizacionalmente nos legislativos para, com uma estrutura mais forte, dar 
conta de disputas majoritárias. Embora sejam raros os partidos novos que concorram em pleitos majoritários, parte deles, caso tenham expressivas lideranças carismáticas, podem chegar ao comando do Poder Executivo Federal logo na primeira eleição. Porém, o que os dados e a história política demonstram é que partidos que se tornam governo sem nenhuma estabilidade organizacional anterior e, ainda muito voltados à figura de seu fundador, tendem a ter pouca estabilidade quando colocados no conflito do sistema competitivo. Sua força inicial fica superdimensionada pela figura do líder que o constrói; e as mesmas razões de seu súbito sucesso (uma estrutura organizacional menos rígida) logo se transformam nas razões de sua fraqueza institucional. Nesse sentido, é impossível se fortalecerem organizacionalmente, podendo construir um caminho efetivo de avanço e de aumento de desempenho. Como, em geral, ganham com posicionamentos mais agressivos contra o sistema político, uma vez estando à frente do comando do governo, precisam moderar seus discursos, o que pode ocasionar diretamente a sua dissolução.

Para o estudo de novos partidos e de seu perfil, a literatura tem apontado para fatores variados ao tentar explicar os seus canais de formação, adaptação e mudanças em relação ao sistema partidário estabelecido. Formações distintas levarão consequentemente a padrões distintos de comportamento e de apoio eleitoral aos novos partidos (BOLLEYER; BYTZEK, 2013). O padrão de formação inicial de um partido determina se este terá sucesso ao longo do processo de competição política ou se será desfeito ou integrado a outros partidos rapidamente. A organização inicial do partido será determinante para que se previna da queda no seu desempenho eleitoral, da perda de espaço no campo político e, consequentemente, se irá conseguir se consolidar como ator competitivo no sistema político. Nesse sentido, a análise aqui empreendida confere mais peso às variáveis de formação e organização do partido para entender o seu desempenho do que outros fatores, como ideologia ou contestação do sistema. 
Os padrões mais conhecidos são, em primeiro lugar, aqueles constituídos pelas chamadas famílias partidárias, formadas por novos partidos de tipos mais específicos, como os partidos verdes na Europa ou partidos plurinacionais em países da América do Sul (KITSCHELT, 1989; POGUNTKE, 2002; KROUWEL; LUCARDIE, 2008). O padrão de partidos, como os verdes, e as direitas populistas radicais têm recebido bastante atenção dos pesquisadores por seu caráter de contestação do status quo e por trazerem, ainda, novas pautas ao debate político. Esse padrão específico tem a limitação metodológica de reduzir a análise a essas "novas questões", não conseguindo explicar partidos que se formam sem apresentar "novas questões" ou fuga desse status quo.

Uma segunda linha de estudos metodologicamente orientada por uma análise mais institucional busca explorar como esses novos partidos se estabelecem "organizacionalmente" e como o seu perfil organizacional pode ser determinante para que este avance em seu sucesso inicial ou se mantenha com níveis de desempenho eleitoral próximo a seu inicial (BOLLEYER; BYTZEK, 2013). Desse modo, analisando o modelo de formação inicial dos partidos, é possível compreender como se dará o seu desenvolvimento em eleições posteriores. A base de sustentação dos novos partidos é garantida desde a sua formação inicial e, em geral, o seu perfil institucional inicial irá conduzir suas possibilidades de desempenho e acordos institucionais dentro da competição política.

Quando formados, novos partidos buscam aumentar o seu desempenho eleitoral e, no limite do possível, manter o percentual de apoio inicial. Como conseguir chegar a essas metas vai depender de como estruturam o apoio político, ou seja, aquilo que Strøm e Müller (1999) chama de perseguir votos, cargos ou políticas. A estratégia adotada pelo partido inicialmente é essencial para determinar sua competitividade. As escolhas feitas pelos novos partidos determinam o seu acesso a diversos recursos institucionais como, por exemplo, partidos mais voltados a compor base de formação de governos tendem a focar mais na conquista de cargos públicos que viabilizem a sua atuação. Já partidos mais ideológicos perseguem políticas e partidos 
com menos enraizamento, buscando apenas votos para garantir a sua manutenção no sistema político. Obviamente, um partido pode combinar as suas metas e intentar cargos e políticas ou unir a busca por políticas a votos para reeleição, por exemplo. Cada cenário irá gerar um aspecto distinto da formação partidária e determinar a sua sobrevivência e desenvolvimento no sistema partidário.

Com o propósito de entender como novos partidos conseguem se sustentar dentro da competição política, Mudde (2007) examina mais extensamente a organização partidária de partidos populistas de direita. Assim, o tipo de organização inicial funciona como um elemento de extrema importância para um sucesso inicial e para que os novos partidos consigam se manter institucionalmente, garantindo, assim, o apoio de suas bases. Mudde (2007) chama atenção para a organização partidária, no sentido de mais de explicar a persistência dos partidos de direita do que o seu avanço eleitoral propriamente. Muitos estudos associam diretamente organização partidária ao sucesso eleitoral, mas deixam de elucidar, de forma mais sólida, quando o partido falha eleitoralmente, não indicando as variáveis que interferem, de fato, no fortalecimento da organização partidária. Uma organização inicialmente ruim traz um mau desempenho político, ou o mau desempenho político impede o partido de se tornar uma organização forte? (MUDDE, 2007, p. 265). Explicar a organização desses partidos é, portanto, fundamental para se entender o desempenho eleitoral dos mesmos.

Unindo a importância dos fatores organizacionais, temos os estudos clássicos sobre a origem e o desenvolvimento dos partidos. Variáveis relacionadas à origem dos partidos e a seu espaço dentro da arena da competição já foram extensamente estudadas, principalmente por Duverger (1967) e Panebianco (2005). Esses autores fundamentam as suas teorias baseando-se na origem dos partidos (interna ou externa ao parlamento) e como se desenvolvem a partir dessa origem. Esse modelo incorpora variáveis políticas (organização partidária, filiação, entre outros) e variáveis sociológicas (alinhamento eleitoral). Enfatizam que as origens dos partidos são um fator importante em sua formação e evolução a médio e 
longo prazo, influenciando fortemente a capacidade de atuação dos partidos. Os autores apontam para os efeitos da rotina e da formação de processos intraorganizacionais como parte significativa da consolidação de partidos a longo prazo.

Portanto, a organização inicial do partido e o seu desenvolvimento vão determinar se é desenvolvido independentemente da força de suas lideranças iniciais, se irá concentrar seu desempenho em lideranças que deram início ao partido ou criará mecanismos para se desenvolver além de seu núcleo formador e das lideranças que o compõe inicialmente. A "rotinização" das ações do novo partido e a difusão de valores relacionados a essa organização constituirão a sua sustentação a longo prazo. A rotina é criada quando o processo dentro do partido começa a ser guiado por regras mais gerais, com regularidade e com menos idiossincrasias por parte de suas lideranças. A difusão de valores se torna o ponto onde os membros partidários começam a cuidar da organização do partido, dispondo deste meio para atingir as metas, mesmo quando há internamente conflitos individuais. Quanto mais o partido cria uma rotina de ações e aumenta o processo intraorganizacional de valores, mais se guia por regras gerais e menos determinado pelas escolhas das lideranças, contribuindo para sua maior "institucionalização" (PANEBIANCO, 2005, p. 49 e 53).

Embora se ressalte a importância de tais teorias para o campo da organização política, o modelo criado por esses autores é pensado em relação a democracias estabelecidas, cabendo à organização dos partidos efeitos distintos quando pensados em democracias recentes (BOLLEYER; BYTZEK, 2013).

Em termos de questão estrutural, partidos recém-criados tendem a ser menos organizados do que partidos já estabelecidos (aqueles que dão início ao sistema partidário) e, por isso mesmo, inclinam-se a compor governos do que os partidos já estabelecidos. Embora o poder de transação seja menor, a sua organização interna comporta melhor a produção de coalizão entre suas lideranças mais do que em partidos que já têm estruturas mais complexas e interesses mais bem definidos (ALLERN; BALE, 2011; LUCARDIE; 
GHILLEBAERT, 2008). Uma vez que consegue se consolidar por meio de uma agenda dentro do governo, esses partidos podem fortalecer a sua estrutura ao longo do tempo. Os amplos recursos existentes na arena de governo configuram incentivos fortes para a ampliação do partido e o fortalecimento de sua construção partidária, que gera incentivos coletivos para conseguir apoio de atores políticos na construção da organização do partido.

Dois fatores irão afetar o formato geral do partido e terão influência direta sobre as suas estratégias possíveis: a organização partidária em primeiro lugar, por fortalecer o partido contra pressões existentes no cargo público (parlamentar ou na esfera de governo), possibilitando maior coordenação deste com a resolução de conflitos e a manutenção de sua sobrevivência a ambientes políticos altamente competitivos, além de sua "institucionalização", parte substantiva para que o novo partido possa lidar com as pressões de competição que colocam em risco o seu desempenho eleitoral, podendo afetar a própria sobrevivência no sistema político (BOLLEYER; BYTZEK, 2013). Juntos, a organização e a institucionalização do partido determinam grande parte do sucesso e de como o partido irá se manter no sistema partidário. Com tendências a ganhar espaço, é possível, assim, manter-se nos níveis de desempenho iniciais ou mesmo ser eliminado por ausência de desempenho.

Em sistemas multipartidários, a entrada de novos partidos gera incertezas tanto na formação de coligações eleitorais quanto na formação da coalizão de governo. Por isso mesmo, a forma como o partido se organiza inicialmente define parte considerável de seu poder de barganha na formação de governo, no seu acesso aos benefícios do cargo e na sua influência na competição política. Como salientam Grotz e Weber (2015), a performance dos novos partidos na formação do governo é altamente relevante se olharmos pela perspectiva da teoria democrática e dos partidos políticos. Isso porque o poder de influência de um novo partido determina tanto o seu poder de sobrevivência quanto as mudanças em relação à agenda política de novos governos. Embora os novos partidos tenham desvantagem em relação a aqueles estabelecidos no sentido 
organizacional e de recursos, estes trazem incertezas à formação de governo e à governabilidade, tornando-se, então, atores estratégicos.

Maior ou menor nível de desempenho eleitoral e desenvolvimento na organização dos novos partidos determinam o nível de incerteza trazida na barganha pela formação de governos, determinando também a sua sobrevivência no jogo político, bem como o seu desempenho através do tempo.

A partir dessas definições, buscamos entender empiricamente como os novos partidos surgidos no sistema político brasileiro têm-se constituído como organizações que buscam se fortalecer, conquistando bases de apoio eleitorais e lideranças que fortaleçam sua sobrevivência ao longo do tempo. A estrutura criada pelos partidos denota mais nitidamente o seu sucesso eleitoral do que as "novas questões" trazidas por seus membros, os quais buscam contestar o status quo dos partidos estabelecidos. Como já dito, apenas as questões antissistema não dão conta de explicar a sobrevivência de novos partidos, já que grande parte deles não se fundamenta unicamente nesse aspecto.

\section{Método de pesquisa}

Mapeamos todos os partidos surgidos desde $1986^{11}$ por meio da análise de cada eleição. A tabela abaixo aborda este panorama descritivo.

Tabela 1 - Partidos novos e partidos "mortos"

\begin{tabular}{ccc}
\hline Ano-eleição & Partidos novos & Partidos mortos \\
\hline 1982 & PMDB/PDS/PTB/PDT/PT & PP** \\
\hline 1986 & PFL/PL/PCB/PDC/PC do B/PSB/PSC & \\
\hline 1990 & PRN-PTC/PSDB/PTR-PP/PST/PMN & \\
\hline 1994 & PV/PRP & PDC**PRS/PST* $^{*}$ \\
\hline 1998 & PST/PSL/PRONA & PRN-PTC $^{*}$ PTR-PP/PRP* \\
\hline
\end{tabular}

11 Não incluímos o ano de 1982 na análise pelo fato de todos os partidos serem novos pela legislação eleitoral de 1979, o que "inflaria" os dados. 


\begin{tabular}{lcc}
\hline 2002 & PSDC & \\
\hline 2006 & PRN-PTC/PSOL/PHS/PT do B/PAN/PR** & PST**PSL*/PSDC* $^{*}$ \\
\hline 2010 & PSL/PRTB/PRB & PRONA $^{* *} /$ PAN $^{* *}$ \\
\hline 2014 & PSD/PRP/PSDC/PEN/PROS/SD/PTN & \\
\hline 2018 & Partido Novo/ Rede \\
\hline $\begin{array}{l}\text { Fonte: elaboração própria a partir dos dados do Tribunal Superior Eleitoral (TSE). } \\
\text { Legenda: *0 partido continuou registrado no TSE, mas sem assento na Câmara dos Deputados. } \\
\text { **0 partido "morreu" por fusão. }\end{array}$
\end{tabular}

A partir desse mapeamento, identificamos todos(as) os(as) deputados(as) federais eleitos(as) nesses partidos. Obtivemos, assim, um universo de 326 deputados(as) e coletamos informações sobre eles em dois aspectos distintos. Primeiramente, construímos uma base para analisar o background dos eleitos pelos novos partidos. Por meio do site de dados abertos da Câmara dos Deputados em que consta a biografia dos deputados por legislatura, identificamos algumas variáveis tais como: (i) a sua filiação anterior (quando existia) ${ }^{12}$; (ii) se já concorreu a algum cargo eletivo anteriormente e qual foi o $\operatorname{cargo}^{13}$; (iii) o seu desempenho eleitoral no partido que concorreu anteriormente (quando havia) e a colocação eleitoral no novo partido ${ }^{14}$.

Em um segundo momento, analisamos mais detidamente as variáveis político-institucionais, como a bancada eleita pelos novos partidos, a magnitude dos distritos onde concorrem e o tipo de entrada (se coligado ou isolado), todos retirados da base de dados eleitorais do Tribunal Superior Eleitoral (TSE).

Com esses dados, buscamos demonstrar as diferenças na formação de partidos que conseguem cooptar parlamentares que já tinham filiação e cargos eletivos antes de migrarem ou que tenham

12 Para parlamentares sem uma biografia muito clara no site da Câmara, recorremos a seus sites pessoais ou do partido para identificar sua atuação anterior à entrada no partido novo. Site de biografias - https://www2.camara.leg.br/deputados/pesquisa. Se ele não tinha se filiado a nenhum partido anteriormente, ele é classificado como sem partido.

13 Também para a identificação do cargo anterior, buscamos em sites pessoais ou dos partidos quando a informação era inexistente no site da Câmara dos Deputados.

14 Também recorremos ao site de biografias da Câmara dos Deputados e conferimos as informações por meio dos dados eleitorais do TSE. 
concorrido a um cargo eletivo com nomes que, até então, não estavam inseridos na política (em partidos ou estruturas institucionais). A magnitude do distrito, o seu desempenho eleitoral e o tipo de entrada serviram como variáveis políticas para o controle desse tipo de opção de formação dos referidos partidos.

Nas seções seguintes, descrevemos os principais aspectos das diferentes formas de escolha estratégica dos partidos e seu sucesso.

\section{Estratégias de entrada: entre a cooptação de lideranças e o lançamento de novos atores políticos}

A formação, o desenvolvimento, a continuidade e a estabilidade têm sido temas centrais para a análise institucional dos sistemas partidários. Desenvolvimento e mudança nos partidos foram bastante analisados por uma vasta literatura (ALDRICH, 1995; BLYTH; KATZ, 2005; KATZ; MAIR, 1993; KIRCHHEIMER, 1966; BARNEA; RAHAT, 2010). Tais estudos possibilitaram avanços também sobre a ideia de realinhamento crítico dos sistemas partidários desenvolvidos tanto no contexto americano (ALDRICH, 1995; BURNHAM, 1965, 1970; PAULSON, 2000) quanto no contexto europeu (BARTONLINI; MAIR, 1990; DALTON, 1984, 2002; DALTON,1984; MAIR, 1997), mas sem desenvolver uma análise mais focada sobre quão de fato "novos" eram os partidos surgidos desse realinhamento.

Partidos são instituições que se modificam para se adaptar ao ambiente da competição, e essa mudança varia na extensão (os níveis de mudança) e na natureza (determinados aspectos do partido que são renovados), como demonstram Barnea e Rahat (2010, p. 305). Os autores estabelecem algumas categorias para entender o que, de fato, compreende-se como novidade partidária, estabelecendo critérios como ideologia, novidade no governo (não incumbentes), novidade eleitoral, registro legal, entre outros.

Como nos baseamos aqui em uma definição eleitoral dos novos partidos políticos, a nossa análise se assemelha à de Hug (2001), com a distinção de novos partidos em duas categorias de análise. A primeira é a de que o autor considera como genuinamente novos, ou seja, sem interferência ou apoio de elites de partidos já estabelecidos. 
A literatura aponta para esses partidos como "partidos naturais" de origem externa ao parlamento, por não possuírem, em seus quadros, nomes já em disputa política em períodos anteriores (HARMEL; ROBERTSON, 1985; SIKK, 2005; KROUWEL; LUCARDIE, 2008).

A segunda definição dada por Hug (2001) se relaciona a partidos surgidos de lideranças, que já vinham estabelecidas de partidos anteriores e se agregam em um novo nome por meio de cisão, fusão ou estratégias políticas. Nessa mesma linha, alguns autores, como Bolleyer e Bytzek (2013), van Biezen, Rashkova (2014), consideram essa perspectiva significativa, uma vez que o surgimento de novos partidos em geral contaria com conflitos sobre decisões estratégicas das elites, envolvendo ausência de coordenação e conflitos eleitorais, que, dificilmente, conseguem se manter dentro dos partidos. Já Sikk (2005) desconsidera esse tipo de organização como nova.

Para o caso brasileiro, consideramos que as contribuições teóricas de Hug (2001) ajudam a explicar o surgimento dos novos partidos, no sentido de estratégias distintas gerarem resultados futuros para os partidos, bem como a estrutura existente de oportunidades no sistema político ajuda a entender tanto as suas estratégias quanto o seu constante surgimento.

A composição política de novos partidos no Brasil tem passado por essas duas características diferentes em seu período de formação e tem delimitado, em certa medida, o espaço representativo e o modus operandi desses partidos ao longo de suas trajetórias políticas.

A primeira delas tem um caráter amplamente conhecido, que é do de cooptar lideranças políticas de partidos já estabelecidos, buscando enfraquecê-los em determinados estados e, consequentemente, ganhar o espólio que os congressistas desses partidos trazem. Dessa forma, novos partidos já conseguem angariar amplas bases políticas existentes e expandi-las com um discurso sobre novidade política. Em segundo lugar, a estratégia é o extremo oposto: selecionar nomes que ainda não estiveram presentes nos campos políticos representativos e que componham listas menos competitivas, os quais deem espaço a lideranças realmente novas.

As duas estratégias têm sido cruciais para definir o perfil posterior desses partidos: os que angariam amplo apoio dentro 
do espectro político já estabelecido por conquistarem um espólio político já consolidado conseguem se manter maiores e com mais influência na formação de governos. O grau de cooptação aqui importa - quanto maior o espólio conquistado, maior a influência; quanto menor, poucos recursos de manutenção e menor ganho de representatividade ao longo do tempo. Aqueles que surgem como novidade política total tendem a se manter reduzidos e centralizados nos principais nomes que deram início ao partido. Na figura abaixo, podemos ver, com mais clareza, como são as movimentações de composição dos novos partidos.

Figura 1 - Diagrama de fluxo de migração de parlamentares entre os partidos ${ }^{15}$

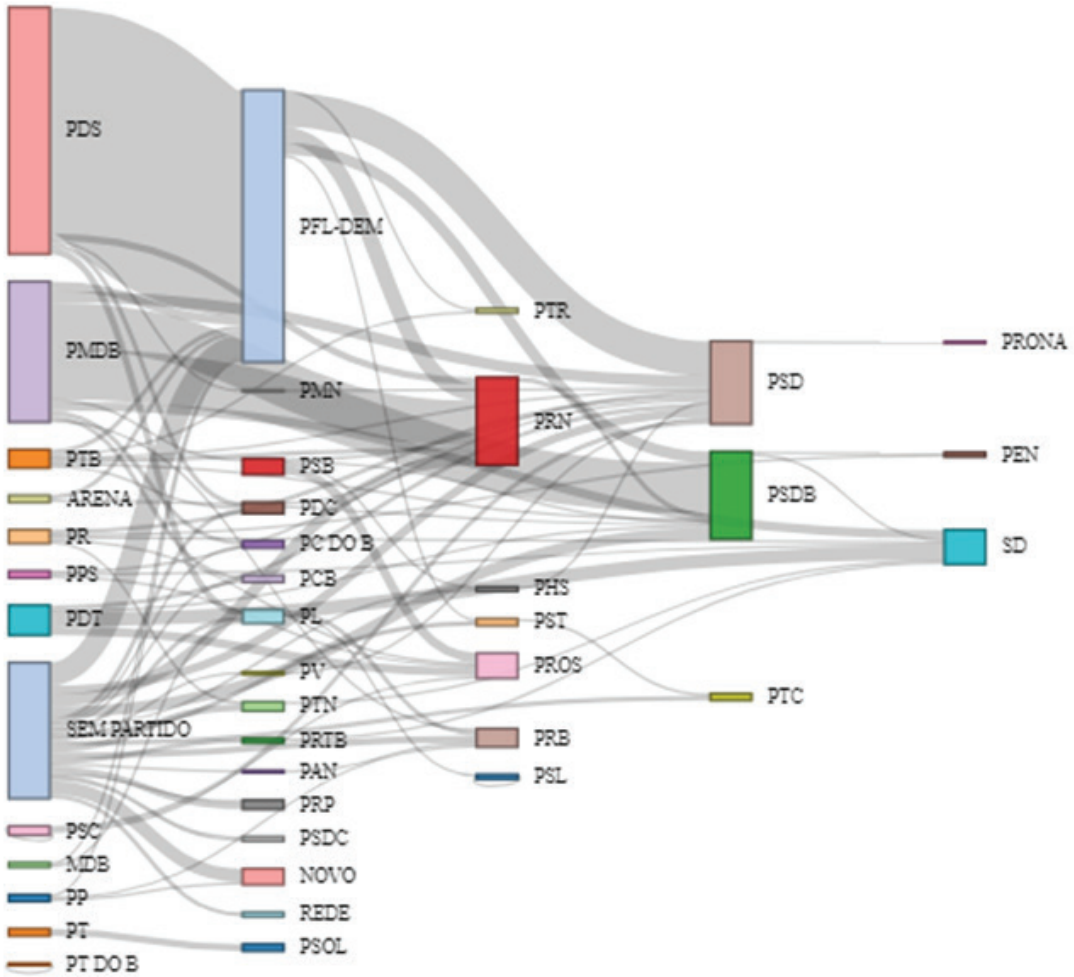

Fonte: elaboração própria com dados do TSE e da Câmara dos Deputados.

15 Quando o partido não possuía filiação anterior, conceituamos como sem partido. 
A Figura 1 nos dá uma visão panorâmica sobre como se mobilizam as elites dos partidos estabelecidos na cooptação e na seleção de nomes para compor os novos partidos. Da esquerda para a direita, a figura demonstra as principais migrações entre partidos. Quanto maior a "barra" e as linhas de conexões, maior a migração. Os que estão pequenos, totalmente à esquerda e sem conexões, além daqueles que saem da posição "sem partido", são os que chamamos de outsiders (ou seja, que seus eleitos não vieram de outros). Já os que não eram filiados a nenhum partido anteriormente estão alocados em sem partido.

Em 1986, em meio aos sete novos partidos surgidos, as estratégias foram no sentido de reorganizar os nomes dispersos nas duas principais siglas que obtiveram o espólio do período autoritário - PDMB e PDS. Entre essas agremiações, a que obteve mais notoriedade foi a formação do PFL, que, já em seu início, torna-se a segunda maior força na Câmara dos Deputados daquele ano, como fica evidente na Figura 1. Nenhum outro partido em eleições teve cooptação de lideranças estabelecidas ao nível do PFL. A estratégia de formação do partido se deu com a retirada de grande parte das lideranças do antigo PDS, a qual angariou ainda alguns nomes do PMDB, PP e PTB. Os outros partidos também seguiram a tática de cooptar nomes de partidos já estabelecidos, porém em menor grau. As siglas tinham o objetivo de conquistar nomes mais próximos de seu espectro ideológico. Como já mencionado, esse plano inicial define grande parte da trajetória posterior dos partidos. O PFL se torna, assim, uma das principais forças pelos próximos anos, e os outros partidos, que nasceram pequenos, mantiveram o desempenho em um nível estável, alcançando algum crescimento, mas nada muito além de se tornar um partido médio, como o PSB, o PSC e o PCdoB.

As eleições de 1990 também trouxeram um elemento de cooptação próximo do ocorrido em 1986, ano no qual o PSDB teve maior proeminência na estratégia de suas elites políticas em abandonar o PMDB, fortalecendo-se em uma nova sigla. O PRN também cooptou muitas lideranças do PMDB e, por sua vez, obteve 
um aumento baseado na popularidade de Fernando Collor de Melo, eleito presidente da República pelo partido, mesmo com uma base parlamentar minoritária. O seu rápido declínio se deu pelo impeachment sofrido pelo nome central do partido, e, com a perda da chefia do governo federal, o partido viu o seu tamanho ser reduzido, restando apenas dois deputados em 1994. Esses dois fatores distintos - um líder carismático e a vitória do principal cargo político em disputa - deram ao partido esse crescimento substantivo, tornando-o distinto dos outros partidos que surgem maiores. Porém, a razão de seu sucesso também se tornou a razão de seu fracasso. Fazer parte de um partido novo sem nenhuma estrutura política nos estados e na Câmara dos Deputados contribuiu para a perda repentina de mandato por meio de um impedimento e afetou seriamente o partido, que, hoje, sob o nome de PTC, mantém-se um partido pequeno. PMN, PST e PTR surgiram conseguindo angariar poucas bases dos partidos estabelecidos e logo "morreram" ou se fundiram a partidos maiores novamente.

As eleições de 1994 a 2006, embora tenham contado com novos partidos, vieram com um baixo nível de cooptação de elites políticas, já que grande parte dos partidos lançou candidatos que não tinham vida pregressa em outros partidos. Como temos visto, a estratégia de surgir como algo totalmente novo não surte tanto efeito no eleitorado, trazendo poucos ganhos ao partido. Partidos que começaram pequenos, mas que conquistaram lideranças já atuantes na Câmara dos Deputados, como o PSOL, por exemplo, que, em 2006, forma-se com a retirada de várias lideranças do PT, tem-se mantido com o desempenho próximo ao inicial.

Em 2010, a eleição volta a assumir esse caráter de cooptação de lideranças na figura do $\mathrm{PRB}$, que, embora não alcance o desempenho eleitoral que o PFL e o PSDB tiveram, consegue uma bancada considerável e mantém um aumento significativo em sua bancada. 
O PRTB e o PSL ${ }^{16}$ conduzem a estratégia de trazer novos nomes, de fora do campo político, o que, como já demonstrado, torna-se uma estratégia que conserva o partido pequeno e com poucas chances de conseguir aumentar o seu desempenho.

Em 2014, houve novamente um aumento substantivo no número de novos partidos, com três novos se formando a partir da retirada estratégica de parte substantiva de elites de outras siglas estabelecidas s, que lhes garantiram força e desempenho eleitoral. O PSD, criado pelo ex-prefeito de São Paulo, Gilberto Kassab, fundou-se da retirada de uma ampla base da elite do DEM. A reorganização foi tão forte que o PSD se tornou um dos maiores partidos do país, enquanto o DEM atestou a sua força totalmente reduzida ${ }^{17}$. O SD (Solidariedade) teve a sua base formada por elites políticas advindas do PDT, que fortaleceram a base sindical na qual o partido se baseia. O PROS também alcançou parte de sua base composta pelo PDT e pelo PSB e em menor escala de outros partidos. Também obteve vantagem por retirada estratégica das principais lideranças desses dois partidos. Outros novos partidos surgiram com a estratégia de trazer caras novas, de fora do espectro político, o que, por sua vez, confirma o seu baixo desempenho eleitoral.

Por fim, embora as eleições de 2018 tenham tido um caráter bastante distinto pela quebra da competição entre PT e PSDB no segundo turno da corrida presidencial, apenas dois novos partidos surgiram. A Rede Sustentabilidade, da ex-senadora Marina Silva, a qual não tinha cumprido o timing necessário de assinaturas em 2014, conquista apenas uma cadeira. Já o partido Novo também surge com nomes de fora do sistema político. Como a tendência geral vista aqui, a probabilidade é que se mantenham nesses níveis iniciais.

16 O PSL ganhou a segunda maior bancada da Câmara em 2018, favorecido pelo fato de disputar a eleição presidencial com um líder carismático que ganhou as eleições. Porém, como já analisado no caso do PRN, a tendência é a de que quando um partido sem nenhuma estrutura organizacional forte chega ao poder acabe tendo dificuldades para conter conflitos intrapartidários e seguir na competição política. Há uma grande probabilidade de enfrentar problemas de organização, retornando ao tamanho inicial assim que perder sua posição de governo.

17 Assim como o PFL fez com o PDS, em 1986. 
A formação de novos partidos assume um caráter então direto com a formação de governos e está associado às disputas entre as elites políticas que compõem o quadro competitivo no sistema partidário como demonstra Lima Júnior (1993). Com a facilidade de criar um partido no início da década de 1980, muitos novos surgiram e, com o tempo, outros maiores acabaram perdendo a capacidade de criar maiorias, tendo de se associar cada vez mais a siglas pequenas. Esse quadro institucional gerou oportunidade política para partidos pequenos com uma quase ausência de coerção, além de incentivos importantes para se associarem a maiorias nos governos.

Assim, a forma como se organizam inicialmente determina sua atuação na estrutura da competição e também a força do desempenho que irá possuir. Desse modo, os partidos novos surgem diretamente ligados à estrutura da competição e, consequentemente, ligados ao Estado e às suas estruturas de incentivos. Caso se tornem situação ou oposição, o nível de organização e cooptação de elites determinam, em grande medida, o desempenho eleitoral desses novos partidos, o nível de influência com que poderão interferir nas políticas de governo, entre outros. Portanto, essas estratégias iniciais são cruciais para que usufruam das estruturas institucionais que lhe são dadas pela estrutura da competição.

A cooptação de elites fortalece o novo partido, possibilitando, efetivamente, um aumento expressivo no total de votos do agente político, que passa para uma outra agremiação, passando a lhe dar também mais liberdade de ação na competição política do que se estivesse em uma sigla estabelecida. O Gráfico 1 demonstra a relação direta existente entre a cooptação de elites políticas de outros partidos e o aumento de ganhos institucionais ao novo partido. 
Gráfico 1 - Relação entre o desempenho dos agentes políticos no partido a que estavam filiados anteriormente e no partido novo ${ }^{18}$

$$
\begin{array}{l|l}
6^{-} & R^{2}=26.4
\end{array}
$$

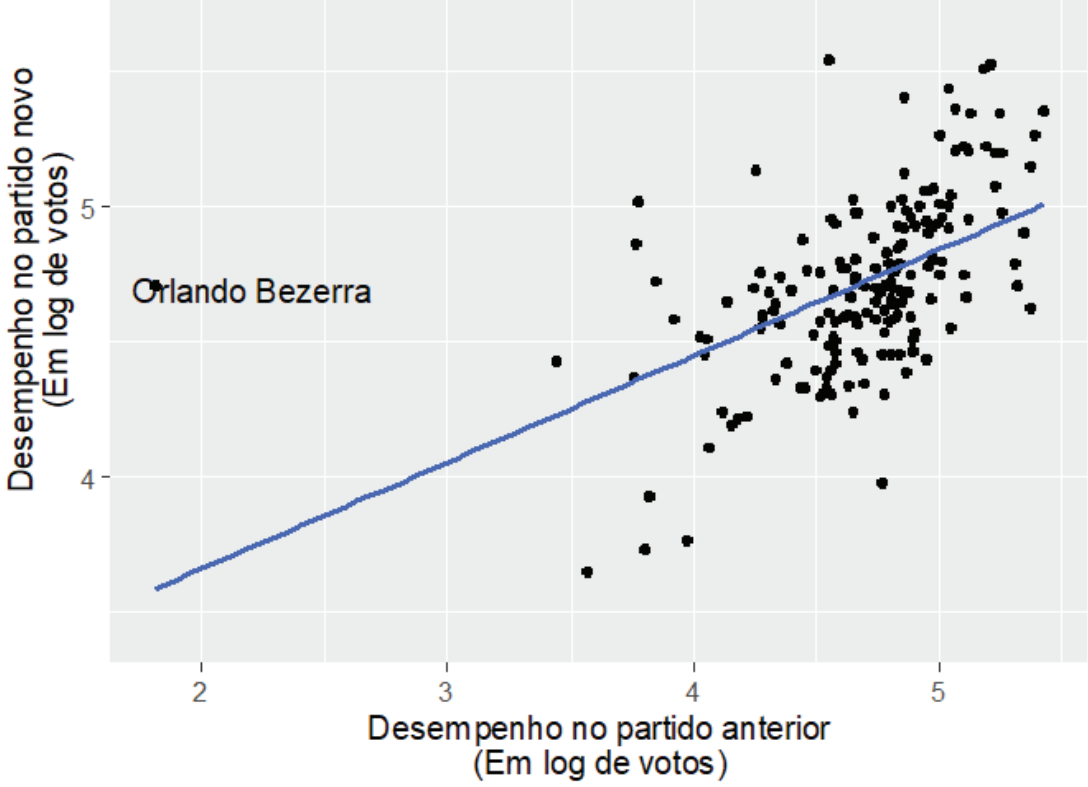

Fonte: elaboração própria a partir dos dados do TSE.

É positiva a relação estabelecida entre o desempenho já conquistado por um determinado agente político que concorreu a um cargo eletivo (deputado federal ou estadual), quando comparado a seu desempenho no novo partido ${ }^{19}$. Assim, ter participado de uma campanha anterior aumenta as chances de o agente político maximizar a sua base de votos e ser eleito, embora, pelo coeficiente de determinação $\left(\mathrm{R}^{2}\right)$, esse modelo explique $26 \%$ da variação entre o desempenho anterior e o desempenho no partido atual. Essa tendência aumenta quando a sigla já é

18 Utilizamos a transformação logarítmica para normalizar os dados, já que há uma diferença muito grande de votos entre as eleições e entre os candidatos. A linha em azul ajusta os dados por grupos.

19 Este gráfico foi plotado com base nos dados de candidatos que já haviam concorrido anteriormente a um cargo de deputado federal ou estadual, que, por conterem o mesmo tipo de fórmula eleitoral (voto proporcional), permitem uma base de comparação. 
conhecida e já possui alguma base política, como é o caso do outlier, que sublinhamos no gráfico. Por exemplo: o deputado federal do Ceará Orlando Bezerra, que foi do PDS para o PFL em 1986, aumentou em mais de seis vezes a sua votação. Plotamos o gráfico sem o nome do deputado, e o coeficiente de correlação se manteve, o que demonstra pouco impacto do outlier no ajuste do gráfico.

Os novos partidos, porém, também conseguem concentrar nomes que não possuíam filiação partidária anterior e que sequer haviam, até então, concorrido a algum cargo eletivo. A comparação de desempenho nesse caso se torna impossível, visto que não há desempenho anterior a ser analisado. Como podemos ver no gráfico a seguir, depois dos deputados federais, outsiders ${ }^{20}$ têm sido os nomes mais viáveis nesses partidos.

Gráfico 2 - 0cupação anterior dos agentes políticos que ingressam nos novos partidos

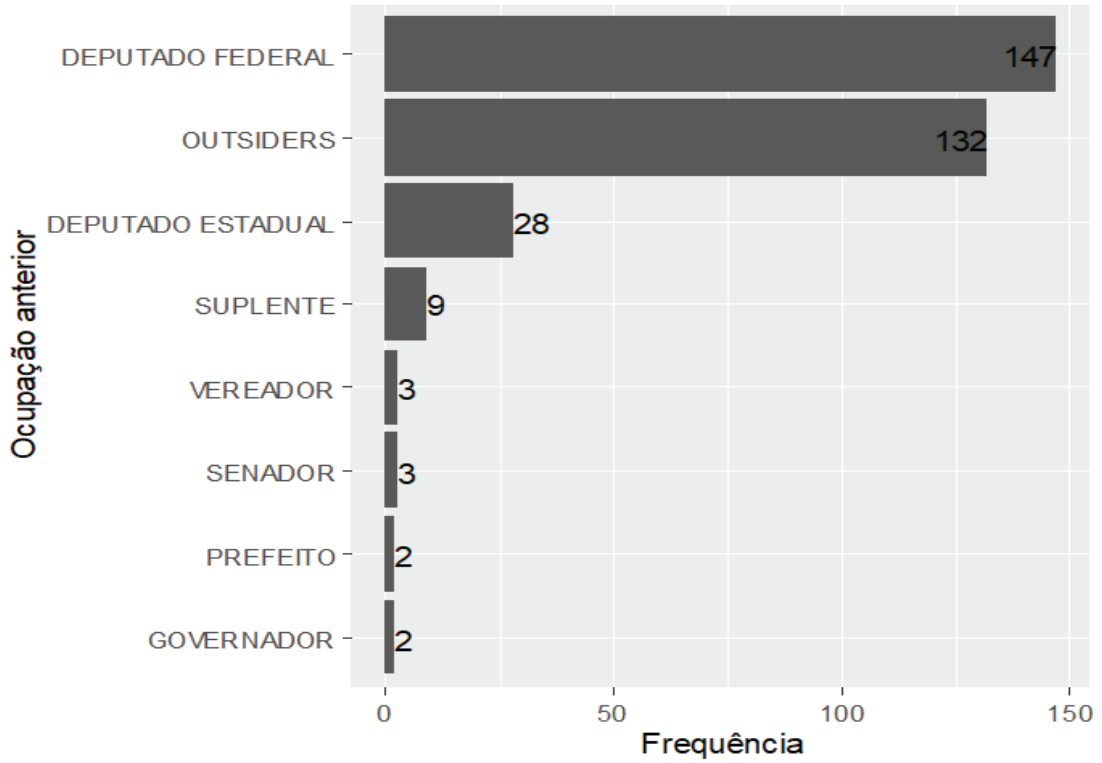

Fonte: elaboração própria a partir dos dados do TSE e da Câmara dos Deputados.

20 A ocupação outsider está condicionada a profissões diversas de cidadãos, as quais não possuíam cargos públicos eletivos anteriormente. Nela, há médicos, advogados, bombeiros, policiais, professores, entre outros. Como existiam profissões distintas, consideramos a categoria outros as demais profissões que vêm de fora da política representativa. 
O Gráfico 2 demonstra que, embora um background político seja de grande importância para se obter um ganho político para os novos partidos, os agentes políticos advindos de fora do sistema representativo também conseguem demonstrar para o eleitorado a possibilidade de inserção no sistema político como novidade na competição. Lideranças diversas com formações distintas - juristas, bombeiros, professores, entre outros - em geral já conhecidas do público, atraem um eleitorado amplo, o qual possibilita aos novos partidos a conquista de uma representação mínima. Temos diversos exemplos nesse sentido, como Lídice da Mata, eleita em 1986 pelo PCdoB; Fernando Gabeira, em 1994; e, atualmente, no Partido Novo observamos nomes que advêm quase, em sua totalidade, de fora do sistema político, embora já estivessem engajados em questões sociopolíticas diversas.

Essas duas estratégias distintas - cooptação de nomes de dentro do sistema representativo e seleção de nomes de fora do sistema têm sido determinantes para predizer o sucesso dos novos partidos em sua trajetória. Nesse ponto, encontramos empiricamente, no caso brasileiro, algo já teoricamente salientado por Hug (2001), que igualmente distingue os partidos de duas formas: (i) aqueles genuinamente novos, ou seja, criados sem apoio de membros de partidos existentes, também chamados de partidos de "formação natural” (HARMEL; ROBERTSON, 1985; BARRETO, 2018); e (ii) aqueles que se formam de cisões ou migrações de outros partidos. Hug recorre, em certa medida, ao conceito de partidos internos ao parlamento e de partidos internos ao parlamento, segundo a formulação de Duverger (1967).

Assim como o entendimento de Hug (2001), a nossa proposição teórica admite que um novo partido é todo aquele que impõe um novo desafio aos que já fazem parte do sistema. Trata-se de uma sigla que está competindo pela primeira vez por votos, que, até então, eram apenas dos partidos estabelecidos, assumindo, portanto, um papel crucial na modificação de forças políticas envolvidas competição. Em uma segunda eleição, o partido já deve ser considerado estabelecido. 
Aliado ao tipo de recrutamento político empreendido pelos novos partidos, as escolhas sobre como distribuir as suas estratégias em relação ao sistema eleitoral e partidário também são fatores determinantes para se compreender o perfil desses partidos ao longo de sua trajetória política, como analisaremos na próxima seção.

\section{Sistema eleitoral e partidário: estratégias partidárias e sucesso de entrada}

O formato inicial dos novos partidos, se construídos a partir da cooptação de elites já estabelecidas, ou por meio de nomes de fora da política, determina também grande parte das estratégias que essas siglas podem utilizar e, consequentemente, o nível de sucesso a ser obtido em relação ao sistema eleitoral. O perfil dos novos partidos oscilou entre um caráter de reorganização de elites, no início do período de restabelecimento da competição, e entre trazer novos nomes de fora do sistema representativo. A partir de 2010, as duas estratégias foram bastante utilizadas, mas o que tem prevalecido é a indicação de novos nomes. Embora, como vimos no Gráfico 2, o número de deputados que vieram de dentro do sistema representativo seja maior, esse quantitativo indica apenas o sucesso dessas elites. O número de novos partidos com nomes novos é maior, ainda que seja menor o sucesso menor dessas siglas.

A partir dessas observações, podemos inferir que as duas estratégias integram o processo de oportunidades políticas estabelecido pelo sistema eleitoral e partidário brasileiro, que delimita as estratégias desses novos partidos. Cooptar nomes já estabelecidos, embora seja a estratégia de mais sucesso, envolve o custo de tentar fazer com que siglas já estabelecidas deixem toda a estrutura partidária que já possuem em um partido maior para embarcar em uma agremiação ainda pouco conhecida e com poucos recursos. Isso só será possível, porém, quando os benefícios de se aliar a esse novo partido se demonstrarem maiores, como, por exemplo: ter mais liberdade para fazer alianças regionais; candidatar-se a cargos majoritários; obter 
maior autonomia no processo eleitoral, entre outros fatores que não disporia em um partido com suas próprias estruturas estabelecidas.

Desse modo, conquistar nomes que venham de fora do sistema político se torna um processo bem mais fácil para os novos partidos, até porque os benefícios são altos e se verifica, também, uma ausência de custos para a entrada desses novos desafiantes. Estar em um novo partido faz com que quadros políticos que já tenham alguma notoriedade social possam fugir de listas muito competitivas de partidos maiores, evitar, ainda, perder os votos conquistados, conseguir mais acesso aos recursos dos partidos, apresentando-se como novidade, entre tantas outras possibilidades.

Estratégias de entrada por magnitude do distrito também afetam o grau de representatividade que o partido conquista. Quando comparados, vemos que há uma relação inversamente proporcional. A bancada eleita nos estados se reduz à medida que os novos partidos passam a ter mais sucesso em estados nos quais a magnitude do distrito é maior. Isso decorre fundamentalmente das estratégias de formação dos partidos. Partidos que têm deputados já cooptados de dentro do sistema político concorrem tanto em distritos de menor magnitude, assim obtendo sucesso e "puxando" mais parlamentares, quanto em distritos de magnitude maior.

Quando novos partidos trazem novos nomes que dispõem de capacidade de angariar votos, mas que ainda não tem nenhum background político, tentam concorrer em distritos de maior magnitude, onde há mais possibilidade de conquistar bases de votos mais espalhadas.

Quanto mais proporcional, melhor seu desempenho. Essa relação pode ser visualizada nos gráficos abaixo. 
Gráfico 3 - Magnitude dos distritos onde partidos que cooptam e outsiders concorrem²

Magnitude dos distribs

onde partidosque cooptam concorrem
Magnitude de dist ito

onde outsiders concorrem
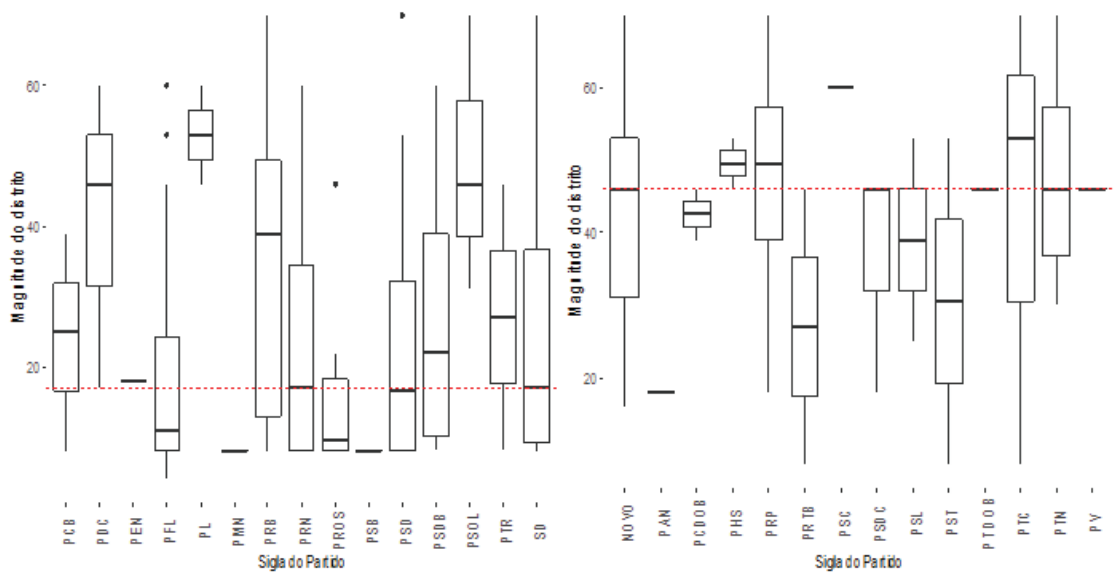

Fonte: elaboração própria a partir de dados do TSE.

Partidos surgidos por meio de cooptação de elites políticas de partidos estabelecidos concorrem em distritos com magnitude que possuem a mediana de 17 cadeiras enquanto os partidos novos que surgem, ou seja, aqueles fora do sistema político, concorrem em distritos com uma mediana de 46 cadeiras.

Essas estratégias afetam diretamente o sucesso desses partidos e a capacidade de ampliar suas bases de apoio, já que, em distritos de baixa magnitude, o percentual de votos necessários para se obter uma cadeira é maior, possibilitando, assim, aos partidos que contam com esse apoio nos distritos a ampliação de suas bases, já que podem dispor de listas competitivas. Já em distritos de alta magnitude, o percentual de votos para ser eleito é reduzido, o que possibilita que candidatos já conhecidos (a exemplo de sindicalistas, jogadores de futebol, radialistas, professores) consigam espalhar as suas bases de votos pelo estado, viabilizando o sucesso de entrada. Embora o partido tenha sucesso, é difícil, porém, possuir uma lista tão competitiva de candidatos, o que faz com que o número de congressistas eleitos em distritos maiores se mantenha reduzido.

21 A linha tracejada em vermelho corta a mediana para o grupo. Partidos que cooptam são aqueles que possuem mais de $50 \%$ de seus representantes eleitos com filiação anterior em outro partido. Partidos com novas lideranças são aqueles em que mais de 50 \% dos eleitos não tinham partidos anteriormente. 
Outro fator de suma importância que incrementa o voto de novos partidos são as coligações feitas nos estados. Atesta-se uma predominância da estratégia de concorrer coligado, principalmente em distritos menores, onde há uma maior probabilidade de novos partidos que cooptam entrarna disputa, coordenando a entrada com coligações. Em distritos maiores, existe uma maior probabilidade de que entrem "isolados", mesmo que essa tendência tenha perdido relevância ao longo dos anos, voltando a ganhar espaço em 2018. Atualmente, competir de modo coligado é uma estratégia importante tanto para distritos menores quanto para distritos maiores. Concorrer em coligações foi, aos poucos, tornando-se estratégia dominante no cenário de disputas legislativas, e, atualmente, pode-se dizer que é uma estratégia obrigatória para que tais partidos conquistem um mínimo de representação.

Gráfico 4 - Estratégia de entrada por magnitude do distrito (1986-2018)22

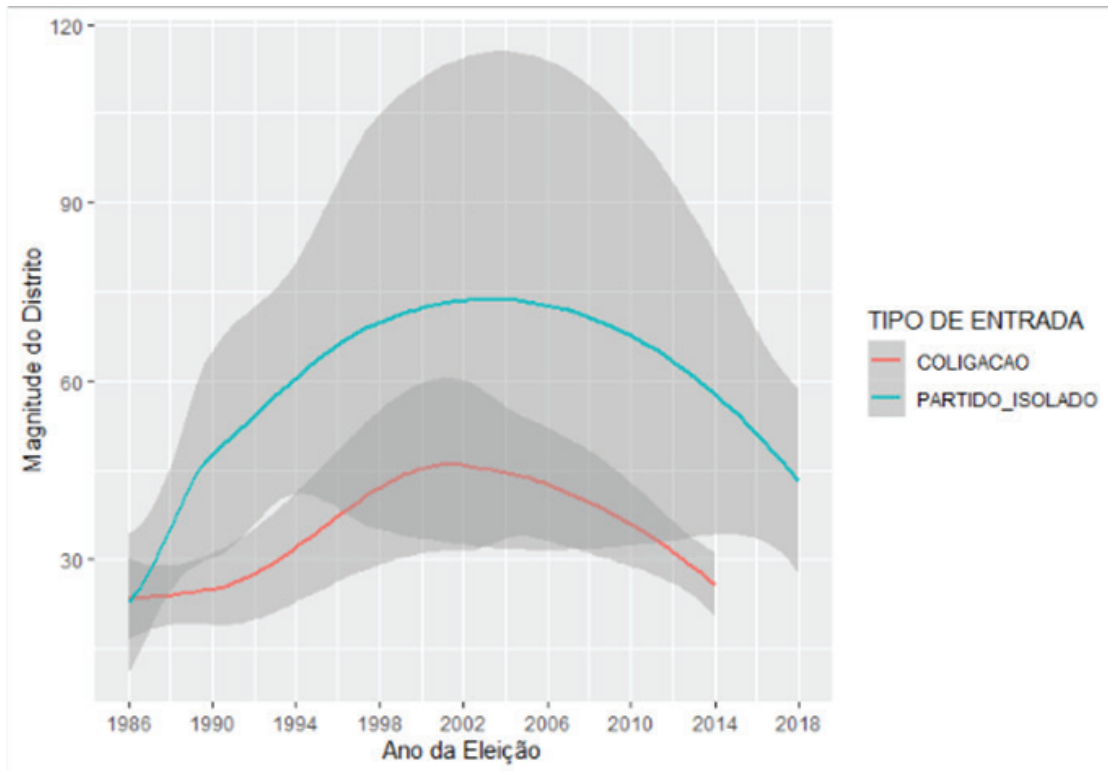

Fonte: elaboração própria a partir dos dados do TSE. 
No período inicial de retorno à competição política, novos partidos, embora concentrassem a maior parte das estratégias de entrada coligados obtinha sucesso, concorrendo em distritos de alta magnitude de forma isolada. Essa estratégia, porém, foi aos poucos sendo abandonada, já que as chances de sucesso de um novo desafiante isoladamente passaram a se tornar cada vez menores. Em 2014, os partidos que concorrem isolados se tornam raros. Em 2018, o Partido Novo volta a utilizar esta estratégia.

O Quadro 1 busca resumir o argumento sobre o sucesso de partidos por seu tipo de origem e estratégias partidárias utilizadas.

Quadro 1 - Sucesso de novos partidos por sua origem de formação e estratégias partidárias.

\begin{tabular}{|c|c|c|}
\hline & \multicolumn{2}{|c|}{ Estratégias partidárias } \\
\hline Estratégias eleitorais & Cooptação de elites & Entrada de novos atores \\
\hline Magnitude do distrito & $\begin{array}{c}\text { Sucesso em todos os distritos, sendo } \\
\text { que os menores contribuem com 0 } \\
\text { aumento de representação }\end{array}$ & $\begin{array}{c}\text { 0 êxito depende da possibilidade de } \\
\text { concorrer em distritos maiores }\end{array}$ \\
\hline Tipo de entrada & $\begin{array}{c}\text { Possibilidade de concorrer de modo } \\
\text { isolado, embora venha se adotando } \\
\text { coalizões como estratégia. }\end{array}$ & Concorrer de modo coligado é parte neces- \\
sária, mas não suficiente de seu sucesso. \\
\hline
\end{tabular}

Fonte: elaboração própria a partir dos dados do TSE.

Quando analisadas em conjuntos, essas duas estratégias (concorrer em distritos de magnitude menor e em coligações) são as que garantem mais sucesso de entrada aos novos desafiantes em partidos que cooptam lideranças políticas, embora também alcancem sucesso em distritos de maior magnitude. Mais uma vez reforçamos que as ações de maior sucesso não são decididas por si só, mas a partir das possibilidades criadas pelos partidos quando no período de sua criação. Além disso, dispor de capacidade de cooptar elites políticas já estabelecidas para que possam fortalecer suas bases, além de aumentar sua representação política, demonstrou-se uma estratégia de maior consolidação desses novos partidos. 
Já em partidos totalmente novos, com nomes formados por quadros de fora do sistema político, a tática que lhes possibilita alcançar êxito é concorrer em distritos de alta magnitude e saírem coligados. Agir contrariamente a isso impele essas siglas a falhas eleitorais e, consequentemente, à ausência de representação de partidos com essa origem. A ausência de nomes mais competitivos faz com que distritos menores, bem como a inexistência de coligações, impacte negativamente sobre o desempenho desses partidos.

Portanto, mais uma vez, a forma como transcorre o processo de construção do novo partido determina as possibilidades estratégicas que irá obter dentro da competição política, consequentemente determinando, assim, a possibilidade de seu sucesso e expansão.

\section{Considerações finais: arena eleitoral e de governo como estruturas de incentivo}

Este artigo buscou compreender como a organização dos novos partidos impacta a sua entrada na competição política e determina o próprio avanço dentro do sistema político. A forma como se organiza o partido, inicialmente, define a sua base de apoio por todo período de sua sobrevivência. Quanto maior a rearticulação entre elites políticas que buscam preencher espaços vacantes no processo político, maior o seu avanço em relação à arena institucional. Independentemente do quanto cada novo partido se distancia do sistema político em relação a novas temáticas colocadas na agenda política, as evidências empíricas nos demonstram que o tipo de organização inicial e as suas habilidades políticas na competição ocasionam, em grande medida, o desempenho do partido ao longo do tempo. Embora não tenhamos analisado outros aspectos dos partidos como ideologia e novos issues, os achados aqui dispostos parecem apontar para o maior impacto das estratégias partidárias no sucesso e na sobrevivência dos partidos do que essas outras variáveis. Acreditamos que essas questões sejam passíveis de uma investigação mais aprofundada em estudos posteriores.

Quando analisada a estrutura da competição, fica claro que as estratégias eleitorais estão ligadas à esfera política e ao processo de 
criação de governabilidade e da estabilidade do governo. A esfera de governo em um sistema multipartidário comporta importante influência na formação de novos partidos justamente por ser estratégia dominante a desarticulação de oposições e reorganização de bases de apoio com lideranças que estavam na oposição. Isto se dá na relação de apoio a lideranças políticas estaduais em troca de base de sustentação no governo federal. Essa reestruturação que se dá entre situação e oposição tem tido forte centralidade na composição do perfil dos novos partidos, pois os que se constroem de dentro do sistema político garantem acesso a recursos e maior base de apoio eleitoral. Aqueles que se declaram totalmente novos têm dificuldade de se distanciar das figuras centrais que deram início ao partido, em geral devido ao carisma dessas lideranças, ou porque demora algum tempo para que o partido consiga construir quadros mais fortes.

As estratégias utilizadas pelos novos partidos vão ser predeterminadas pelo espaço aberto às lideranças políticas dentro da estrutura da competição. Se o partido se constrói, primeiramente, dentro do parlamento e concorre a uma eleição ou vice-versa. A primeira estratégia se apresenta como dominante no sistema político brasileiro, principalmente pela centralidade da relação Executivo-Legislativo, a qual é determinante para a formação da agenda política do governo. Como esse plano se movimenta pela via entre situação-oposição e com o governo, a partir de muitos recursos disponíveis no sentido de coordenar uma ação forte da rearticulação de oposições para partidos que possam se tornar base de governo. Saem na frente os novos partidos com lideranças consolidadas e que conseguem formar grupos mais coesos de modo a influenciar na formação das coalizões.

A arena de governo tem tido uma forte centralidade na competição política por ser o modelo que tem estruturado o apoio de lideranças já consolidadas em partidos que buscam construir agendas alternativas em espaços vacantes de poder no sistema político. Com isso, partidos vêm buscando trazer para a sua base políticos que já disponham de alguma carreira política, constituindo, desse modo, uma estratégia importante para determinar o futuro do partido. 
Como visto, ao longo de nosso período de reabertura política, houve a rearticulação de partidos que migravam em bloco para novos partidos, coordenando estratégias que, em grande medida, iam pelo caminho de passar de oposição a situação, ou mesmo a construção de novas alianças políticas, as quais não seriam possíveis em suas siglas anteriores. A tática de migrar em massa para novos partidos demonstrou-se a mais efetiva, assegurando, assim, força organizacional, além de avanço eleitoral e na expansão das bases. Partidos iniciados com um número reduzido de congressistas acabaram estabelecendo-se dentro da competição política pela manutenção de seu sucesso primeiro, conseguindo, por vezes, aumentar esse apoio.

Já na arena direta da disputa eleitoral, para aqueles partidos que lograram ganhar espaço com nomes novos vindos de fora do mainstream político, obtiveram pouco apoio eleitoral, mantendo, ao longo de sua sobrevivência, o desempenho alcançado quando iniciado e ainda com uma organização partidária muito centralizada na figura dos nomes que motivaram o surgimento do partido. Isso se deu em grande parte porque essas lideranças, em geral, eram nomes carismáticos que conquistavam o apoio de eleitorados bastante específicos, como policiais, bombeiros, professores, artistas, entre outros. Justamente por esses novos partidos que trazem nomes totalmente de fora do meio político serem carismáticos é que se dificultam a organização e o desenvolvimento desses partidos. Com pautas mais específicas, essas lideranças centralizam os recursos, ocasionando, desse modo, uma ausência de formação de um quadro político mais amplo para o partido.

Nesse sentido, a análise empírica do caso brasileiro revela algumas semelhanças com as teorias institucionalistas, as quais analisam como a formação do partido impacta em sua organização e no desenvolvimento ao longo de seu período de sobrevivência, afetando, assim, o sistema político como um todo (HUG, 2001; TAVITS, 2008). A partir dessas informações, construímos subsídios para compreender como a organização de novos partidos pode 
contribuir para o melhor entendimento acerca do impacto dessas organizações nos diversos aspectos do sistema político.

Muito do que se discutiu sobre os novos partidos no Brasil trouxe, porém, pouca contribuição aprofundada sobre essas organizações, o que suscitou a formulação de afirmações relativas à baixa organização e ao enraizamento desses partidos - organizações, portanto, voltadas apenas à manutenção de interesses de poucas elites. Se em alguns casos tais afirmações são verdadeiras, na verdade essas assertivas pouco explicam efetivamente o ambiente de formação e a criação desses partidos. Como demonstramos aqui, o nível de organização inicial e o seu modelo de formação apresentam-se como essenciais para determinar a sobrevivência e o avanço desses partidos no sistema político. Para além de fatores como distinção ideológica dos partidos estabelecidos ou a construção de novas agendas políticas, demonstramos que a organização inicial, bem como a sua relação com o sistema eleitoral, gera tanto o seu campo estratégico quanto o seu tempo de vida no sistema político.

\section{Referências}

ALDRICH, John H. Why parties?: the origin and transformation of political parties in America. Chicago, IL: University of Chicago Press, 1995.

ALLERN, Elin; BALE, Tim.. Political parties and interest groups: disentangling complex relationships. Party Politics, London, v. 18, n. 1, p. 7-25, 2011.

ANDREWS, Josephine T.; MONEY, Jeanette. Champions and challengers: ideology and the success of non-established parties in established party systems. 2003. Paper presented at the Annual Meeting of the American Political Science Association, Philadelphia.

BARNEA, Shlomit; RAHAT, Gideon. Out with the old, in with the "new": what constitutes a new party? Party Politics, London, v. 17, n. 3, p. 303-320, mar. 2010. 
BARRETO, Alvaro Augusto de Borba. Novos partidos: em busca de uma definição conceitual. Revista Brasileira de Ciência Política, Brasília, n. 27, p. 37-72, 2018. DOI: http://dx.doi.org/10.1590/0103-335220182702. Disponível em: http://www.scielo.br/scielo.php?script=sci_ arttext\&pid=S010333522018000300037\&lng=en \&nrm=iso. Acesso em: 4 jun. 2019.

BARTOLINI, Stefano; MAIR, Peter. Identity, Competition and Electoral Availability. Cambridge: Cambridge University Press. (1990).

BIEZEN, Ingrid van; RASHKOVA, Ekaterina R. Deterring new party entry? The impact of state regulation on the permeability of party systems. Party Politics, v. 20, n. 6, p. 890-903, 2014.

BLYTH, M; KATZ, R. "From catch-all politics to cartelisation". West European Politics, vol. 28, no 1, p. 33-60, 2005.

BOIX, Carles. The emergence of parties and party systems. In: BOIX, Carles; STOKES, Susan (ed). Oxford Handbook of Comparative Politics.. New York: Oxford University Press, 2007. p. 314-34.

BOLLEYER, Nicole; BYTZEK, Evelyn. Origins of party formation and new party success in advanced democracies. European Journal of Political Research, Dordrecht, v. 52, n. 6, p. 773-796, 2013. DOI: 10.1111/1475-6765.12013.

BOLLIN, Niklas. New party entrance: analyzing the impact of political institutions. Umea Working Papers in Political Science, n. 2, p. 1-20, 2007.

BOLLIN, Niklas. New party parliamentary entry in Western Europe, 1960-2010. European Journal of Government and Economics, [Online], v. 3, n. 1, p. 5-23, 2014.

BRAGA, Maria do Socorro Sousa. Eleições e democracia no Brasil: a caminho de partidos e sistema partidário institucionalizados. Revista Brasileira de Ciência Política, Brasília, n. 4, p. 43-72, 2012.

BURNHAM, Walter Dean. Critical elections and the mainsprings of American politics. London: W. W. Norton \& Company, 1970. 
BURNHAM, Walter Dean. The changing shape of American political universe. American Political Science Review, Washington, DC, v. 59, n. 1, p. 7-28, 1965.

CHHIBBER, Pradeep;KOLLMAN, Ken. The Formation of National Party Systems: Federalism and Party Competition in Canada, Great Britain, India, and the United States. Princeton, NJ: Princeton University Press. (2004).

DALTON, Russell J. Citizen politics: public opinion and political parties in advanced industrial democracies. 3. ed. Chatham, NJ: Chatham House/Seven Bridges, 2002.

DALTON, Russell J. Cognitive mobilization and partisan dealignment in advanced industrial democracies. Journal of Politics, Malden, v. 46, n. 1, p. 264-284, 1984.

DUVERGER, Maurice. Os partidos políticos. 6. ed. Rio de Janeiro: Zahar Editores, 1967.

GALLAGHER, Michael. Election indices dataset. 2017. Available at: http://www.tcd.ie/Political_Science/staff/michael_gallagher/ ElSystems/index.php. Accessed in: 29 Jan. 2017.].

GROTZ, Florian; WEBER, Till. Newparties, information uncertainty, and government formation: evidence from Central and Eastern Europe. European Political Science Review, Cambridge, v. 8, n. 3, p. 449-472, 2015. DOI: 10.1017/s1755773915000120.

HARMEL, Robert; ROBERTSON, John D. Formation and success of new parties: a cross-national analysis. International Political Science Review, London, v. 6, n. 4, p. 501-523, 1985.

HAUSS, C; D. RAYSIDE (1978) “The development of new parties in western democracies since 1945," pp. 31-57 in L. Maisel and J. Cooper (eds.) Political Parties: Development and Decay. Beverly Hills, CA: Sage.HUG, Simon. Altering party systems: strategic behavior and the emergence of new political parties in Western democracies. Ann Arbor: University of Michigan Press, 2001.

INGLEHART, Ronald. The silent revolution: changing values and political styles among Western publics. Princeton: Princeton University Press, 1977. 
JANDA, Kenneth. Political parties: a cross-national survey. New York: The Free Press, 1980.

KATZ, R; MAIR, P. "The evolution of party organizations in Europe: the three faces of party organization". American Review of Politics, vol. 14, p. 593-617, 1993.

KECK, Margaret. PT, a lógica da diferença: o Partido dos Trabalhadores na construção da democracia brasileira. São Paulo: Ática, 1991.

KESTLER, Thomas; KRAUSE, Silvana, and LUCCA, Juan B. (2013),

Los break-in parties en América Latina: éxito o fracaso? Revista

Debates. Vol. 07, No 02, pp. 159-171.

KRAUSE, Silvana; SCHAEFER, Bruno Marques; BARBOSA,

Tiago Alexandre Leme. Dinâmicas de surgimento de novos partidos na América do Sul (1979-2015). Revista Brasileira de Ciência Política, Brasília, n. 27, p. 73-104, 2018. DOI: http://dx.doi.org/10.1590/0103-335220182703Disponível em: http://www.scielo.br/scielo.php?script=sci_ arttext\&pid=S010333522018000300073\&lng=en \&nrm=iso. Acesso em: 4 jun. 2019.

KINZO, Maria Dalva Gil. Oposição e autoritarismo: gênese e trajetória do MDB. São Paulo: Vozes, 1988.

KIRCHHEIMER, Otto. The transformation of the Western European party systems. In: LA PALOMBARA, Joseph; WEINER, Myron (ed.). Political parties and political development. New Jersey: Princeton University Press, 1966. p. 177-200.

KITSCHELT, Herbert. The logic of party formation, ecological politics in Belgium and West Germany. Ithaca and London: Cornell UP, 1989.

KROUWEL, André; LUCARDIE, Paul. Waiting in the wings: new parties in the Netherlands. Acta Politica, Basingstoke, v. 43, n. 2-3, p. 278-307, 2008.

LAGO, Ignacio; MARTINEZ, Ferran. Why new parties? Party Politics, London, v. 17, n. 1, p. 3-20, 2011.

LIPSET, Seymour Martin; ROKKAN, Stein. Party systems and voter alignments. New York: Free Press, 1967. 
LIMA JÚNIOR, Olavo Brasil de. Democracia e instituições políticas no Brasil dos anos 80. São Paulo: Loyola, 1993. 162 p. LIMONGI, Fernando; CORTEZ, Rafael. As eleições de 2010 e o quadro partidário. Novos estud. - CEBRAP, São Paulo, n. 88, p. 21-37, Dec. 2010. Available from <http://www.scielo.br/scielo. php?script=sci_arttext\&pid=S0101-33002010000300002\&lng=e n\&nrm=iso $>$. access on 03 May 2021. https://doi.org/10.1590/ S0101-33002010000300002.

LUCARDIE, Paul; GHILLEBAERT, Christian-Pierre. The short road to power and the long way back: newly governing parties in the Netherlands. In: DESCHOUWER, Kris (ed.). New parties in government. London: Routledge, 2008. p. 65-85

MAINWARING, Scott. Rethinking party systems in the third wave of democratization: the case of Brazil. Stanford, CA: Stanford University Press, 1999.

MAINWARING, Scott; ESPAÑA-NÁJERA, Annabella; GERVASONI, Carlos. Extra System Electoral Volatility and the Vote Share of Young Parties. 2009. Paper for the Annual Meeting of the Canadian Political Science Association.

MAIR, Peter. Party System Change: Approaches and Interpretations. Oxford: Oxford University Press. (1997)

MELO, Carlos Ranulfo Felix de. Eleições presidenciais, jogos aninhados e sistema partidário no Brasil. Revista Brasileira de Ciência Política, Brasília, n. 4, p. 13-41, 2010.

MELO, Carlos Ranulfo Felix de; CÂMARA, Rafael. Estrutura da competição pela presidência e consolidação do sistema partidário no Brasil. DADOS - Revista de Ciências Sociais, Rio de Janeiro, v. 55, n. 1, p. 71-117, 2012.

MENEGUELLO, Rachel. PT: a formação de um partido 1979-1982. São Paulo: Paz e Terra, 1989.

MUDDE, Cas. Populist radical right parties in Europe. Cambridge: Cambridge University Press, 2007.

MUSTILLO, Thomas J. Modeling new party performance: a conceptual and methodological approach for volatile party systems. Political Analysis, Oxford, n. 17, p. 311-332, 2009. 
PANEBIANCO, Angelo. Modelos de partido: organização e poder nos partidos políticos. São Paulo: Martins Fontes, 2005. PAULSON, Arthur. Realignment and Party Revival: Understanding American Electoral Politics at the Turn of the Twenty-First Century. Westport, CT: Praeger. (2000).

PEDERSEN, Mogens N. On measuring party system change: a methodological critique and a suggestion. Comparative Political Studies, Thousand Oaks, v. 12, n. 4, p. 387-403, 1980.

POGUNTKE, T. Green parties in national governments: From protest to acquiescence? Environmental Politics, 11, 133-145. (2002)

SIKK, Allan. How unstable? Volatility and the genuinely new parties in Eastern Europe. European Journal of Political Research, Dordrecht, v. 44, p. 391-412, 2005.

STRØM, Kaare; MÜLLER, Wolfgang C. Political parties and hard choices. In: MÜLLER, Wolfgang C.; Strøm, Kaare (ed.). Policy, office, or votes? How political parties in Western Europe make hard decisions. Cambridge: Cambridge University Press, 1999. p. 1-35.

TAROUCO, Gabriela. Institucionalização partidária no Brasil (1982- 2006). Revista Brasileira de Ciência Política, Brasília, n. 4, p. 169-186, 2010.

TAVITS, Margit. Party system change: testing a model of new party entry. Party Politics, London, v. 12, n. 1, p. 99-119, 2006.

TAVITS, Margit. Party systems in the making: the emergence and success of new parties in new democracies. British Journal of Political Science, Cambridge, v. 38, n. 1, p 113-133, 2008.

\section{Resumo:}

Este artigo busca demonstrar, por meio de análise do caso brasileiro, como a estratégia de formação dos novos partidos determina sua capacidade de sobrevivência na competição e de seu nível de desempenho eleitoral ao longo do tempo. Com dados originais, evidenciamos dois tipos de estratégias utilizadas pelos partidos: (i) cooptação das elites políticas de partidos grandes; e (ii) criação de um partido com nomes novos dentro 
do sistema político. Introduzimos uma inovação ao debate indicando que as estratégias partidárias no momento de formação têm tido um peso relevante para explicar seu sucesso de formação e nível competitivo. Utilizamos dados biográficos dos (as) parlamentares na Câmara dos Deputados e dados eleitorais para dar conta de explicar as diferenças no tipo de estratégias de formação e no sucesso desses novos partidos. Com isso, contribuímos para preencher uma lacuna no estudo sobre novos partidos no Brasil, fenômeno tão conhecido, mas pouco estudado.

Palavras-chave: Novos partidos; organização partidária; coordenação eleitoral; representação política; comportamento político.

\section{Abstract:}

This article seeks to demonstrate, through the analysis of the Brazilian case, how the creation strategy of new political parties determines their ability to survive competitively and their level of electoral performance over time. Based on original data, we show how the understanding the creation strategy of new parties is essential for understanding their future impact on political competition. We innovate in the debate by indicating that party strategies at the moment of the creation have played a relevant role in explaining their evolution and competitive success. We use biographical data from parliamentarians in the Chamber of Deputies and electoral data to explain the differences in the type of training strategies and the success of these new parties. In doing so, we contribute to filling a gap in the study of new parties in Brazil, a well-known, but little studied phenomenon.

Keywords: New parties; political organization; electoral coordination; political representation; political behavior.

Recebido em 25 de junho de 2020

Aprovado em 30 de março de 2021 